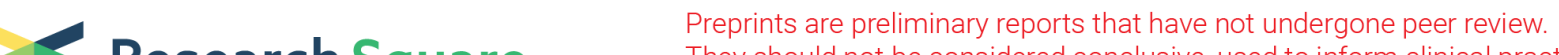 Research Square They should not be considered conclusive, used to inform clinical practice, or referenced by the media as validated information.
}

\section{Dysgeusia Due to Zinc Deficiency After Pancreaticoduodenectomy Requiring Continuous Intravenous Zinc Supplementation: a Case Report and Literature Review}

Hironobu Hata ( $\sim$ hatabooh@gmail.com )

National Hospital Organization Hokkaido Cancer Center https://orcid.org/0000-0002-0077-7026

\section{Yojiro Ota}

Shizuoka Cancer Center: Shizuoka Kenritsu Shizuoka Gan Center

Katsuhiko Uesaka

Shizuoka Cancer Center: Shizuoka Kenritsu Shizuoka Gan Center

Yutaka Yamazaki

Hokkaido University

Tsubasa Murata

Tomakomai City Hospital

Chika Murai

Hokkaido University

Kazuhito Yoshikawa

Hokkaido University

Kenji Imamachi

National Hospital Organisation Hokkaido Cancer Center: Hokkaido Gan Center

Takashi Yurikusa

Shizuoka Cancer Center: Shizuoka Kenritsu Shizuoka Gan Center

Yoshimasa Kitagawa

Hokkaido University

\section{Case report}

Keywords: Zinc deficiency, Dysgeusia, Pancreaticoduodenectomy, Total parenteral nutrition, Postoperative nutrition management

Posted Date: October 18th, 2021

DOI: https://doi.org/10.21203/rs.3.rs-957498/v1 
License: (c) (i) This work is licensed under a Creative Commons Attribution 4.0 International License. Read Full License 


\section{Abstract}

Background: Zinc is mainly absorbed in the duodenum and proximal jejunum, which are removed during pancreaticoduodenectomy (PD). Little is known about the adverse oral events and skin disorders caused by zinc deficiency after PD. Herein, we reviewed studies regarding the development of zinc deficiency after PD and presented the case of a patient with zinc deficiency after PD, who required home intravenous zinc replacement.

Case presentation: A 73-year-old woman with glossitis, taste disorder, and acrodermatitis enteropathicalike eruption on her fingers presented to the Division of Dentistry and Oral Surgery 69 days after PD. Her serum zinc level markedly decreased to $30 \mu \mathrm{g} / \mathrm{dL}$. Oral zinc administration was inadequate to treat hypozincemia after PD; therefore, multi-trace elements were injected intravenously under readmission. Her serum zinc levels recovered, and the lesions gradually improved. Furthermore, a central venous port was implanted to maintain normal serum zinc levels, and she continued self-injecting zinc at home.

Conclusion: Zinc deficiency after PD rarely occurs. The clinical oncologist community, including dentists responsible for the oral care of cancer patients, should be aware of dysgeusia associated with zinc deficiency after cancer surgery, as well as that induced by chemotherapy or head and neck radiation therapy.

\section{Background}

Zinc is an essential trace element for humans, which when deficient can cause various pathological conditions, such as dermatitis, hair loss, anemia, dysgeusia, impaired development, gonadal dysfunction, and wound healing disorders. The role of zinc in taste functions is appreciable at various levels of body organization, such as taste buds and the taste sensation transmission [1]. Zinc deficiency secondary to any etiology leads to taste disturbances; thus, zinc depletion is corrected for patients presenting with taste imbalances [2]. It has been observed in vivo that zinc administration improves decreased taste bud cell proliferation caused by zinc deficiency [3]. Zinc administration improves taste in $50-82 \%$ of patients suffering from taste disorders [4]. Dysgeusia during cancer treatment is mainly reported in systemic chemotherapy and in surgery and radiation therapy for head and neck cancer [5]. However, there are a few reports of taste disorders secondary to zinc deficiency associated with surgery in other regions of the body.

Pancreaticoduodenectomy (PD) is the standard operation for periampullary cancers. Zinc is primarily absorbed in the duodenum and proximal jejunum, which are mostly resected during PD $[6,7]$ and may result in nutritional sequelae due to zinc deficiency [8]. Armstrong et al. reported that the incidence of zinc deficiency after PD is 50\% [9]. Yu et al. reported that $68 \%$ of the patients in their study had low serum zinc levels, and $43 \%$ exhibited clinical symptoms related to zinc deficiency following PD [10]. However, the frequency of taste disorders was not described in either study. The incidence of zinc deficiency with acrodermatitis enteropathica after PD is approximately $0.3 \%$ in a high-volume hospital [8]. 
Little is known about the adverse oral events and skin disorders caused by zinc deficiency after PD. Therefore, we describe the case of a patient who experienced zinc deficiency with dysgeusia, glossitis, and acrodermatitis enteropathica-like eruption after PD.

\section{Case Presentation}

A 73-year-old woman who had pancreatic head adenocarcinoma underwent pancreatoduodenectomy (PD) at the Division of Hepato-Biliary-Pancreatic Surgery, Shizuoka Cancer Center Hospital, Shizuoka, in July 2005. The patient's height, body weight, and body mass index were $154 \mathrm{~cm}, 56 \mathrm{~kg}$, and $23.6 \mathrm{~kg} / \mathrm{m}^{2}$, respectively. The patient was discharged 40 days after surgery; however, about a month after discharge, she visited the hospital's Division of Dentistry and Oral Surgery with a chief complaint of tongue pain with dysgeusia. The first intraoral examination revealed complete atrophy of the lingual papillae, which became erythematous; this is a symptom of glossitis (Fig. 1a). Furthermore, remarkable taste disorder (hypogeusia) and oral pain were reported. The angle of the mouth had stomatitis with erosive changes. The extremities showed acrodermatitis enteropathica-like eruption and abnormal keratinization (Fig. 1b). Blood test results showed hypoproteinemia (total protein (TP) $5.1 \mathrm{~g} / \mathrm{dL}$, albumin (ALB) $2.4 \mathrm{~g} / \mathrm{dL}$ ) (Table 1). Examination of trace elements showed remarkably lower serum zinc and copper levels $(30 \mu \mathrm{g} / \mathrm{dL}, 40$ $\mu \mathrm{g} / \mathrm{dL}$, respectively) (Table 1). We diagnosed malnutrition, dysgeusia, glossitis, angular cheilitis, and acrodermatitis enteropathica due to zinc deficiency.

Table 1

Data of blood tests at the time of initial examination

\begin{tabular}{|llllll|}
\hline TP & $\mathbf{5 . 1} \mathbf{g} / \mathrm{dL}$ & WBC & $\mathbf{7 0 3 0} / \mu \mathrm{L}$ & AST & $\mathbf{4 5} \mathrm{IU} / \mathrm{L}$ \\
\hline $\mathrm{ALB}$ & $2.4 \mathrm{~g} / \mathrm{dL}$ & RBC & $400 \times 10^{6} / \mu \mathrm{L}$ & ALT & $46 \mathrm{IU} / \mathrm{L}$ \\
\hline $\mathrm{Zn}$ & $30 \mu \mathrm{g} / \mathrm{dL}$ & $\mathrm{Hb}$ & $12 \mathrm{~g} / \mathrm{dL}$ & ALP & $368 \mathrm{IU} / \mathrm{L}$ \\
\hline $\mathrm{Cu}$ & $40 \mu \mathrm{g} / \mathrm{dL}$ & $\mathrm{Ht}$ & $36.2 \%$ & $\mathrm{CEA}$ & $18 \mathrm{ng} / \mathrm{mL}$ \\
\hline $\mathrm{Zn} / \mathrm{Cu}$ ratio & 0.75 & $\mathrm{PLT}$ & $16.7 \times 10^{6} / \mu \mathrm{L}$ & $\mathrm{CA} 19-9$ & $15 \mathrm{U} / \mathrm{mL}$ \\
\hline $\begin{array}{l}\text { TP: total protein, ALB: albumin, Zn: zinc, Cu: copper, WBC: white blood cell, RBC: red blood cell, Hb: } \\
\text { hemoglobin, Ht: hematocrit, PLT: platelets, }\end{array}$ & & & \\
\hline
\end{tabular}

Initially, we orally administered $150 \mathrm{mg}$ of Promac ${ }^{\circledR}$ granules $15 \%$ (polaprezinc, ZERIA Pharmaceutical Co., Ltd, Japan) per day (total zinc dose, $34 \mathrm{mg} /$ day) to treat the zinc deficiency. However, due to the insufficient effectiveness of the replacement therapy, we additionally administered multi-trace elements (MTEs) for high-calorie infusions. Elemenmic ${ }^{\circledR}$ (Ajinomoto Co Inc, Japan) was administered intravenously, 1 ampule of which included ferric chloride $9.460 \mathrm{mg}$, manganese chloride $0.1979 \mathrm{mg}$, zinc sulfate hydrate $17.25 \mathrm{mg}$, copper sulfate $1.248 \mathrm{mg}$, potassium iodide $0.1660 \mathrm{mg}$, elemental iron (Fe) 35 
$\mu \mathrm{mol}$, manganese (Mn) $1 \mu \mathrm{mol}$, zinc (Zn) $60 \mu \mathrm{mol}$ (= $4 \mathrm{mg}$ ), copper (Cu) $5 \mu \mathrm{mol}$, and iodine (I) $1 \mu \mathrm{mol}$; this was administered twice a week for two weeks as an outpatient treatment. However, the intravenous replacement therapy was similarly inadequate at this dosing interval and did not provide sufficient improvement in the serum copper and zinc values. The blood test results four months after PD were as follows: TP, $4.4 \mathrm{~g} / \mathrm{dL} ; A L B, 2.0 \mathrm{~g} / \mathrm{dL} ; \mathrm{Zn}, 34 \mu \mathrm{g} / \mathrm{dL}$; and $\mathrm{Cu}, 28 \mu \mathrm{g} / \mathrm{dL}$; the patient required nutritional management during hospitalization with total parenteral nutrition (TPN). An improvement was observed in the zinc level $(99 \mu \mathrm{g} / \mathrm{dL})$ and copper level $(204 \mu \mathrm{g} / \mathrm{dL})$ after 20 days of administering 1 ampule of Elemenmic ${ }^{\circledR}$ per day. Concurrently, her tongue pain and dysgeusia gradually improved. Because of a similar improvement in her nutritional status, she completed TPN (TP $5.1 \mathrm{~g} / \mathrm{dL}$, ALB $2.5 \mathrm{~g} / \mathrm{dL}, \mathrm{Zn} 99$ $\mu \mathrm{g} / \mathrm{dL}, \mathrm{Cu} 204 \mu \mathrm{g} / \mathrm{dL}$ ). A central venous catheter (CVC) inserted after admission was removed and she was discharged 20 days after admission.

Intravenous zinc replacement therapy was discontinued simultaneously with the second discharge. One month after discharge, the serum zinc level decreased sharply, her oral pain increased again, and she had reduced food intake (Zn $35 \mu \mathrm{g} / \mathrm{dL}, \mathrm{Cu} 44 \mu \mathrm{g} / \mathrm{dL}$ ). We administered Promac ${ }^{\circledR} 150 \mathrm{mg}$ per day; however, no improvement was observed in her symptoms, and the patient was readmitted at the end of December 2005. To improve malnutrition, a CVC was re-inserted through the external jugular vein and injected with the MTE formulation and high-calorie infusions on consecutive days for 4 weeks (TP $5.9 \mathrm{~g} / \mathrm{dL}$, ALB 3.4 $\mathrm{g} / \mathrm{dL}$, Zn $75 \mu \mathrm{g} / \mathrm{dL}$, Cu $47 \mu \mathrm{g} / \mathrm{dL}$ ). In January 2006, since her oral pain and diet had improved, she was discharged from the hospital after receiving an implant of a central venous port, and she continued home self-injection of MTEs to maintain zinc levels. In February 2006, her taste function tended to improve, and in April 2006, the taste almost improved. When MTEs were self-injected daily, the serum zinc level gradually exceeded the normal range and reached $167 \mu \mathrm{g} / \mathrm{dL}$ in August 2006; therefore, the administration was switched to every other day. Subsequently, we had to confirm the blood test data repeatedly to monitor serum zinc levels to ensure that they were within the normal range (Fig. 2). Despite continuing intravenous zinc replacement therapy, serum zinc levels decreased when additional oral zinc was discontinued in May 2007. After resuming the oral administration of Promac® due to the recurrence of dysgeusia, both the serum zinc level and dysgeusia improved. Since 2008, Pancreatin ${ }^{\circledR}$ (pancreatic enzyme, Mylan Co Inc, USA) $3 \mathrm{~g} /$ day had been administered alongside conventional zinc administration for this patient.

As of January 2012 , she continued using Elemenmic ${ }^{\circledR}$ intermittently while her serum zinc values were monitored; however, slight angular cheilitis was observed, and she exhibited no signs of glossitis and dysgeusia (Fig. 1C). Moreover, recurrence and metastasis of the primary tumor were not observed. She subsequently died of lung cancer in May 2020.

\section{Discussion And Conclusion}

There are few reports on postoperative taste loss in gastrointestinal cancer, and the involvement of zinc deficiency has not been investigated [11]. Since its introduction in 2002 at the Shizuoka Cancer Center Hospital, PD had been performed in approximately 45 patients per year until 2007; however, only the 
patient in this study experienced severe dysgeusia caused by zinc deficiency. In fact, dysgeusia and skin lesions caused by zinc deficiency following PD have not been assessed in quality-of-life studies [12-15]. The most common technique for PD consists of the en-bloc removal of the distal segment (antrum) of the stomach, the duodenum, the proximal part of the jejunum, the head of the pancreas, the common bile duct, and the gallbladder. Zinc is mainly absorbed in the duodenum and proximal jejunum, which are resected during PD, subsequently causing zinc deficiency. In the study by Yu et al., one patient developed zinc deficiency with a serum zinc level of $32 \mu \mathrm{g} / \mathrm{dL} 15$ months after surgery. During hospitalization, zinc was supplemented intravenously, and the patient was discharged after an oral administration of pancreatic enzymes. Another patient developed zinc deficiency with a serum zinc level of $29 \mu \mathrm{g} / \mathrm{dL} 4$ years after surgery [8]. The patient required the continuous administration of zinc sulfate and pancreatic enzyme formulations. In a study by Yazbeck et al., the patient developed zinc deficiency with a serum zinc level of $42 \mu \mathrm{g} / \mathrm{dL} 3$ years after surgery. The patient was discharged after an oral administration of 50 $\mathrm{mg} /$ day of zinc sulphate. Only in our case has oral zinc supplementation been inadequate, requiring continued intravenous zinc supplementation to maintain the normal serum zinc level. Although the details are unknown for other cases, the upper $15 \mathrm{~cm}$ part of the jejunum was surgically removed in this patient. Supposedly, conserved jejunum and ileum absorb zinc usually, and it is unclear why oral administration was inadequate in our case. Yu et al. and Yazbeck et al. proposed three mechanisms for zinc deficiency after PD $[8,16]$ : 1) impaired zinc absorption associated with jejunectomy; 2 ) insufficient protein absorption after PD; and 3) impaired fractional absorption of zinc due to pancreatic insufficiency, which is improved by exocrine pancreatic replacement [17]. Insufficient protein absorption after PD is because zinc is transported in the serum via carrier proteins, namely ALB ( $57 \%$ of serum zinc), alpha-2macroglobin (40\%), and amino acids, such as histidine and cysteine ( $<3 \%$ [8]. Consequently, poor protein absorption may cause low zinc availability. Moreover, deficiencies in branched-chain amino acids and essential fatty acids may contribute to the formation of skin lesions similar to those of acrodermatitis enteropathica observed in patients with zinc deficiency $[18,19]$. From a therapeutic viewpoint, the clinical manifestation of zinc deficiency in PD might be improved not only by supplementation with zinc but also by the administration of pancreatic enzyme formulations and adequate intake of protein and essential fatty acids [8].

In 2017, Nobelzin ® tablet 50 mg (zinc acetate hydrate 167.84 mg, Nobelpharma Co. Ltd., Tokyo, Japan), which had been proven to be safe and effective for the long-term treatment of Wilson disease [20], was approved for the additional indication of hypozincemia in Japan [21]. The gastric ulcer healing agent Promac ${ }^{\circledR} 150 \mathrm{mg}$ could be supplemented with $34 \mathrm{mg}$ of zinc daily, while zinc replacement was an offlabel use. Now, for zinc replacement therapy, 3 tablets of Nobelzin ${ }^{\circledR}$ could be supplemented with at most $150 \mathrm{mg}$ of zinc, which is more than four times as much zinc supplement as the standard dose of $150 \mathrm{mg}$ of Promac $\circledast$ daily. The difference in bioavailability between zinc acetate hydrate and polaprezinc is unclear; however, in a study of zinc supplement for hemodialysis maintenance patients, $50 \mathrm{mg}$ of zinc per day administered in the zinc acetate hydrate group was superior to $34 \mathrm{mg}$ of zinc per day administered in the polaprezinc group in increasing and maintaining serum zinc levels [22]. It is unclear whether higher oral zinc supplementation with zinc acetate hydrate could replace intravenous zinc supplementation in 
our case. A limitation of this study is that the findings are not generalizable. Further research elucidating the probable causes of zinc deficiency after PD is required to improve the generalizability of our study findings.

Zinc deficiency after PD rarely occurs, and the mechanism has not been fully elucidated; the clinical oncologist community, including dentists responsible for the oral care of cancer patients, should be aware of dysgeusia associated with zinc deficiency after cancer surgery, as well as that induced by chemotherapy or head and neck radiation therapy.

\section{List Of Abbreviations}

PD, Pancreaticoduodenectomy; MTE, multi-trace elements; CVC, central venous catheter; TPN, total parenteral nutrition; TP, total protein; ALB, albumin

\section{Declarations}

\section{Ethics approval}

This study was performed on human participants were in accordance with the ethical standards of the institutional and national research committee and with the 1964 Helsinki declaration and its later amendments or comparable ethical standards.

\section{Consent to participate}

Not applicable

\section{Consent for publication}

Not applicable.

\section{Availability of data and material}

All data generated or analysed during this study are included in this published article

\section{Code availability}

Not applicable

\section{Conflict of interest}

All authors have no conflict of interest to declare that are relevant to the content of this article.

\section{Funding}

No funding was received to assist with the preparation of this manuscript. 


\section{Author contributions}

All authors contributed to the study conception and design. The manuscript was drafted by [Hironobu Hata], [Yojiro Ota], and [Katsuhiko Uesaka]. The data was acquired by [Murai Chika], [Tsubasa Murata], [Kazuhito Yoshikawa] and [Kenji Imamachi]. The analysis and data interpretation were conducted by [Yutaka Yamazaki], [Takashi Yurikusa], and [Yosihimasa Kitagawa]. All authors read and approved the final manuscript.

\section{Acknowledgements}

We would like to thank Miho Ota, the wife of Yojiro Ota, for consenting to the publication on behalf of the deceased (https://doi.org/10.1007/s00520-013-1943-z). We thank Editage (www.editage.jp) for editing and reviewing this manuscript for English language.

\section{References}

1. Bhattacharya PT, Misra SR, Hussain M. Nutritional aspects of essential trace elements in oral health and disease: An extensive review. Scientifica. 2016;2016:5464373.

2. Henkin RI. Zinc in taste function: A critical review. Biol Trace Elem Res. 1984;6:263-80.

3. Kinomoto T, Sawada M, Ohnishi Y, Yamaguchi T, Tsuge S, Ogawa S, et al. Effects of polaprezinc on morphological change of the tongue in zinc-deficient rats. J Oral Pathol Med. 2010;39:617-23.

4. Kodama H, Tanaka M, Naito Y, Katayama K, Moriyama M. Japan's Practical Guidelines for zinc deficiency with a particular focus on taste disorders, inflammatory bowel disease, and liver cirrhosis. Int J Mol Sci. 2020;21:2941.

5. Hovan AJ, Williams PM, Stevenson-Moore P, Wahlin YB, Ohrn KE, Elting LS, et al. A systematic review of dysgeusia induced by cancer therapies. Support Care Cancer. 2010;18:1081-7.

6. Hambidge M. Human zinc deficiency. J Nutr. 2000;130:1344S-9S.

7. Krebs NF. Overview of zinc absorption and excretion in the human gastrointestinal tract. J Nutr. 2000;130:1374S-7S.

8. Yu HH, Shan YS, Lin PW. Zinc deficiency with acrodermatitis enteropathica-like eruption after pancreaticoduodenectomy. J Formos Med Assoc. 2007;106:864-8.

9. Armstrong T, Walters E, Varshney S, Johnson CD. Deficiencies of micronutrients, altered bowel function, and quality of life during late follow-up after pancreaticoduodenectomy for malignancy. Pancreatology. 2002;2:528-534.

10. Yu HH, Yang TM, Shan YS, Lin PW. Zinc deficiency in patients undergoing pancreatoduodenectomy for periampullary tumors is associated with pancreatic exocrine insufficiency. World J Surg. 2011;35:2110-7.

11. Welchman S, Hiotis P, Pengelly S, Hughes G, Halford J, Christiansen P, et al Changes in taste preference after colorectal surgery: A longitudinal study. Clin Nutr. 2015;34:881-4. 
12. Huang JJ, Yeo CJ, Sohn TA, Lillemoe KD, Sauter PK, Coleman J, et al. Quality of life and outcomes after pancreaticoduodenectomy. Ann Surg 2000;231:890-8.

13. Fong ZV, Alvino DM, Castillo CF, Nipp RD, Traeger LN, Ruddy M, et al. Health-related quality of life and functional outcomes in 5-year survivors after pancreaticoduodenectomy. Ann Surg 2017;266:68592.

14. Allen CJ, Yakoub D, Macedo FI, Dosch AR, Brosch J, Dudeja V, et al. Long-term quality of life and gastrointestinal functional outcomes after pancreaticoduodenectomy. Ann Surg 2018;268:657-64.

15. van Dijk SM, Heerkens HD, Tseng DSJ, Intven M, Molenaar IQ, van Santvoort HC. Systematic review on the impact of pancreatoduodenectomy on quality of life in patients with pancreatic cancer. HPB. 2018;20:204-15.

16. Yazbeck N, Muwakkit S, Abboud M, Saab R. Zinc and biotin deficiencies after pancreaticoduodenectomy. Acta gastroenterol Belg. 2010;73:283-286.

17. Easley D, Krebs N, Jefferson M, Miller L, Erskine J, Accurso F, et al. Effect of pancreatic enzymes on zinc absorption in cystic fibrosis. J Pediatr Gastroenterol Nutr. 1998;26:136-9.

18. Kim YJ, Kim MY, Kim HO, Lee MD, Park YM. Acrodermatitis enteropathica-like eruption associated with combined nutritional deficiency J Korean Med Sci. 2005;20:908-911.

19. Templier I, Reymond JL, Nguyen MA, Boujet C, Lantuejoul S, Beani JC, et al. [Acrodermatitis enteropathica-like syndrome secondary to branched-chain amino acid deficiency during treatment of maple syrup urine disease]. Ann Dermatol Venereol. 2006;133:375-9.

20. Shiomura J. Nobelpharma, a new Japanese pharmaceutical company that only provides medicines for unmet medical needs. J Thoracic Dis. 2014;6:E125-9.

21. Katayama K, Hosui A, Sakai Y, Itou M, Matsuzaki Y, Takamori Y, et al. Effects of zinc acetate on serum zinc concentrations in chronic liver diseases: a multicenter, double-blind, randomized, placebocontrolled trial and a dose adjustment trial. Biol Trace Elem Res. 2020;195:71-81.

22. Okamoto T, Hatakeyama S, Konishi S, Okita K, Tanaka Y, Imanishi K, et al. Comparison of zinc acetate hydrate and polaprezinc for zinc deficiency in patients on maintenance hemodialysis: $A$ single-center, open-label, prospective randomized study. Ther Apher Dial. 2020;24:568-77.

\section{Figures}




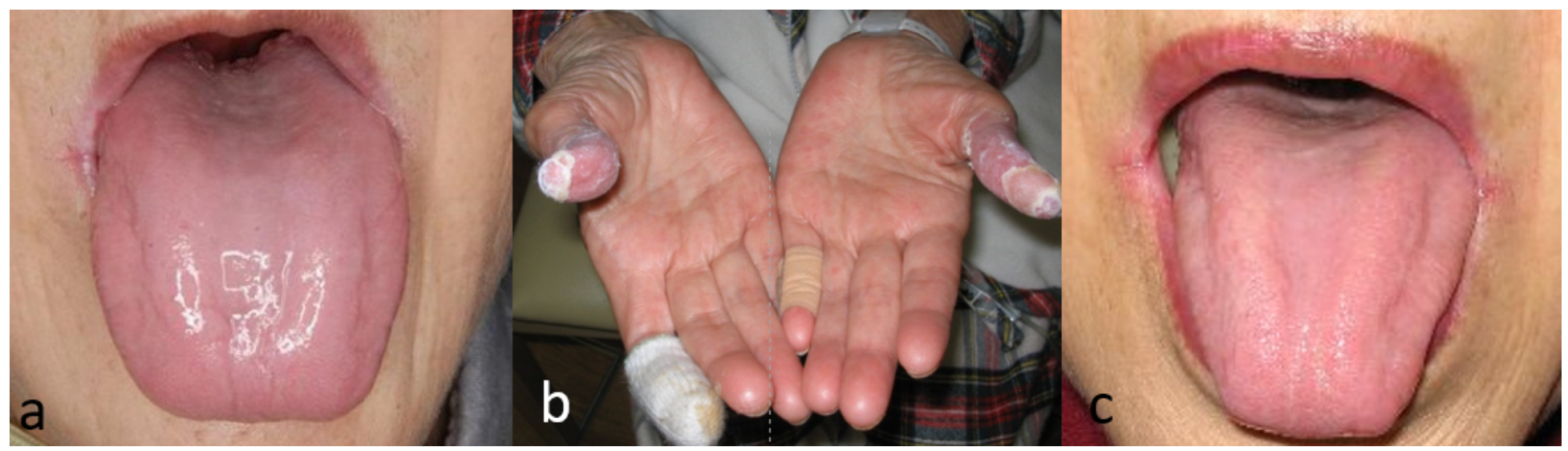

\section{Figure 1}

a. Glossitis with atrophy of the lingual papillae and erythema. b. Picture of the bilateral thumbs showing acrodermatitis enteropathica-like eruption and abnormal keratinization. c. Picture showing improved atrophy of the lingual papillae as a result of proper zinc supplementation, but refractory angular cheilitis

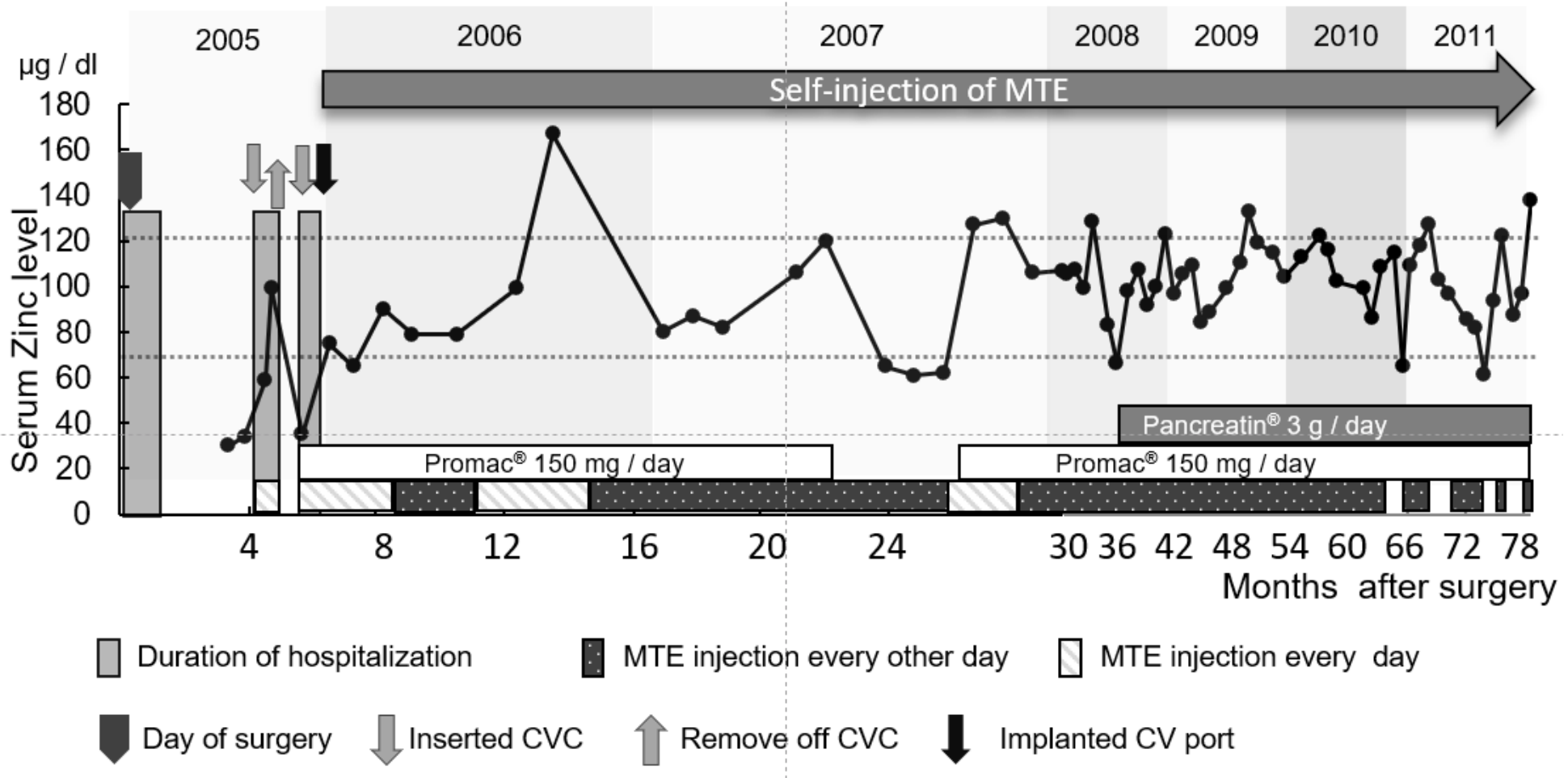

Figure 2

Transition of zinc supplementation and serum zinc level. Approximately one month after discharge following pancreaticoduodenectomy performed in July 2005 , the patient experienced oral pain and dysgeusia caused by zinc deficiency (serum zinc level, $30 \mu \mathrm{g} / \mathrm{dL}$ ). Oral zinc supplementation was inadequate, and dietary intake decreased; therefore, she was admitted to the hospital in November 2005 and administered intravenous supplementation of multi-trace elements (MTEs), including zinc and highcalorie infusion. Serum zinc level increased to $99 \mu \mathrm{g} / \mathrm{dL}$, and food intake improved; hence, she was 
discharged 20 days after admission following intravenous zinc supplementation. However, after discharge from the hospital, intravenous zinc supplementation was discontinued, and she became hypozincemic again within a month; therefore, she was readmitted to the hospital at the end of December 2005. At the second discharge in January 2006 , a central venous port was indwelled, and home selfinjection of MTEs was performed to maintain zinc levels. 